\title{
Effect of Austenite Grain Size on Sulfide Stress Cracking Resistance of Low Alloy Martensitic Steels
}

\author{
Hitoshi ASAHI and Masakatsu UENO
}

Yawata R \& D Laboratory, Nippon Steel Corporation, Tobihata, Tobata-ku, Kitakyushu, Fukuoka-ken, 804 Japan.

(Received on February 24, 1992; accepted in final form on June 19, 1992)

\begin{abstract}
Effect of grain size on sulfide stress cracking (SSC) resistance, thought to be an important metallurgical factor, is not clearly understood. There are some conflicting experimental results about grain size effect on SSC resistance. In this paper, effect of austenite grain size of low alloy tempered martensite steel was investigated using a constant load SSC test, considering their correlation with chemical compositions. An $R s$ value (SSC threshold stress/yield strength) begins to decrease with increase in yield strength at the yield strength equal to $\sigma_{c}^{85}$. Fractographic study reveals that $\sigma_{c}^{85}$ corresponds to the minimum yield strength for the occurrence of intergranular fracture. $\sigma_{c}^{85}$ rises with refinement in austenite grains, while $R s$ is not affected by austenite grain size at yield strengths below $\sigma_{c}^{85} \cdot \sigma_{c}^{85}$ at a constant grain size is influenced also by chemical compositions. When $R s$ is plotted against its tensile strength, no effect of austenite grain size, however, appears. The proposed model shows that grain refinement strengthening apparently increases $\sigma_{c}^{85}$.
\end{abstract}

KEY WORDS: sulfide stress cracking; low alloy steel; austenite grain size.

\section{Introduction}

Increasing demand of deep sour wells requires high strength tubulars with good resistance to sulfide stress cracking (SSC). SSC is a phenomenon of particular concern to oil and gas producers and refiners whose high strength drill pipes, production tubulars and other steel equipment can be subjected to failure when in contact with acid brines containing hydrogen sulfide $\left(\mathrm{H}_{2} \mathrm{~S}\right){ }^{1}$ ) Extensive research concerning SSC has been performed and has made it clear that SSC is a manifestation of hydrogen embrittlement. During the research, correlations between SSC resistance and metallurgical factors, particularly alloy effects, have been made clear to some extent, resulting in a successful development of high strength SSC resistant tubulars with specified minimum yield strengths of $90 \mathrm{ksi}(617 \mathrm{MPa})$ and $95 \mathrm{ksi}(652$ $\mathrm{MPa}){ }^{2-6)}$ Further intensive metallurgical research on SSC made it possible to develop high strength SSC resistant tubulars with specified minimum yield strengths of $100 \mathrm{ksi}(686 \mathrm{MPa})$ and $105 \mathrm{ksi}(720 \mathrm{MPa}) .{ }^{7)}$ However, metallurgical factors controlling SSC resistance still have not been fully understood. Among them, the ef- fect of austenite grain size is not clear, though it has been investigated because hydrogen embrittlement of high strength steel occurs accompanying intergranular cracks. There are still conflicting observed results in the literature. ${ }^{8,9)}$

The principal purpose of the present investigation is to understand the influence of the austenite grain size of low alloy tempered martensite steels on the SSC considering their correlation with chemical compositions.

\section{Experimental Procedure}

\subsection{Materials and Heat Treatment}

All heats of steels used in this study were melted in a vacuum induction furnace and cast into 50 or $100 \mathrm{~kg}$ ingots. The chemical compositions are listed in Table $\mathbf{1}$. $\mathrm{Mn}$ and Mo vary in content while the other elements are substantially the same in content. The ingots were cut in two along the middle plane of the section so as to avoid the influence of center segregation. The cut ingot were heated at $1523 \mathrm{~K}\left(1250^{\circ} \mathrm{C}\right)$ for $1 \mathrm{~h}$, subsequently hot rolled to 12 to $14 \mathrm{~mm}$ thick plate. The austenite grain size was varied by changing austenitizing conditions.

Table 1. Chemical compositions of steels. (wt \%)

\begin{tabular}{ccccccccccccc}
\hline Steel & C & Si & Mn & P* & S* & Cr & Mo & Nb & Al & Ti & $N^{*}$ & $B^{*}$ \\
\hline HC & 0.20 & 0.05 & 1.46 & 120 & 10 & 0.49 & - & - & 0.028 & 0.018 & 39 & 8 \\
HM & 0.19 & 0.06 & 1.47 & 120 & 20 & 0.52 & 0.20 & - & 0.029 & 0.020 & 40 & 6 \\
LM & 0.20 & 0.05 & 0.51 & 130 & 10 & 0.51 & 0.20 & - & 0.026 & 0.019 & 30 & 14 \\
\hline
\end{tabular}

* [ppm]. 
The plates were austenitized at $1203 \mathrm{~K}\left(930^{\circ} \mathrm{C}\right)$ to $1423 \mathrm{~K}\left(1150^{\circ} \mathrm{C}\right)$ for $30 \mathrm{sec}$ or $15 \mathrm{~min}$, followed by quenching into stirring water. Because every steel used here has enough hardenability, the quenched steel was transformed into full martensite. Then the steels were tempered at various temperatures, followed by water cooling. A salt bath was used for 30 or $60 \mathrm{sec}$ heating while a conventional electric furnace was used for longer heating times.

\subsection{Measurement of SSC Resistance}

The constant load SSC test according to the NACE TM0177-90A ${ }^{10)}$ was conducted to evaluate SSC resistance of steel. Smooth round bars with $6.4 \mathrm{~mm}$ diameter shown in Fig. 1 were machined in the rolling direction after the heat treatment. The tests were performed using dead weight testers, and in the NACE TM0177 solution $\left(0.5 \% \mathrm{CH}_{3} \mathrm{COOH}+5 \% \mathrm{NaCl}\right.$ solution saturated with $1 \mathrm{~atm} \mathrm{H}_{2} \mathrm{~S}$ ). The solution volume of specimen surface area was $30 \mathrm{ml} / \mathrm{cm}^{2}$ and the test temperature was $24 \pm 3^{\circ} \mathrm{C}$. The maximum initial stress at which no failure occurs during the test period of $720 \mathrm{~h}$ is a threshold stress $\left(\sigma_{t h}\right)$, which is adopted as an SSC resistance value. An $R s$ value, a $\sigma_{t h}$ normalized by the yield strength is also used.

\subsection{Fractographic Observation of SSC}

It was difficult to observe microscopically the fracture surface of the specimens subjected to the constant load test because the fracture surface was exposed to the corrosive solution after the failure and damaged due to corrosion. Therefore the constant load tester was equipped with a device which protected the fracture

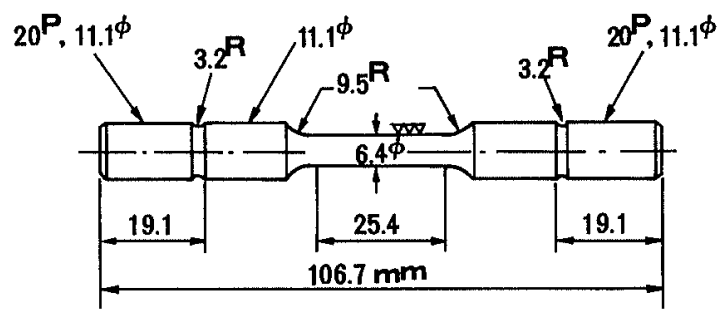

Fig. 1. Constant load SSC test specimen. surface from the corrosion. Immediately after the test specimen failure, supply of $\mathrm{H}_{2} \mathrm{~S}$ gas is stopped. Then the corrosive solution is discharged and alcohol is put into the vessel. This liquid substitution is repeated twice. The process automatically starts by sensing the failure. Thus the fresh fracture surface can be obtained. After pickling the specimen in $10 \% \mathrm{H}_{2} \mathrm{SO}_{4}$ solution with an inhibitor, an SSC fracture surface was examined with a scanning electron microscope (SEM).

\section{Experimental Results}

\subsection{Microstructure and Mechanical Properties}

Examples of prior austenite grains are presented in Fig. 2. Austenite grain size becomes coarse with an increase in austenitizing temperature and prolongation in austenitizing time as shown in Fig. 3. Change of properties with tempering temperature is represented in Fig. 4 for the steel $\mathrm{HC}$; yield strength and tensile strength gradually decrease with increase in tempering temperature. At a constant tempering temperature, yield strength for the finer grains is higher than that for the coarser grains, though little influence on tensile strength exists.

Figure 5 represents extraction replica micrographs of the steels with the same chemical composition, the same strength level and different grain sizes. No particular difference in the size and the distribution of carbides can be observed.

\subsection{Effect of Austenite Grain Size on SSC Resistance}

In Fig. 4, SSC resistance, $R s$ rises up to 0.9 level with increase in tempering temperature. The experimental data in Fig. 4 are replotted in Fig. 6 to see the relation between $R s$ and yield strength. At lower yield strengths, $R s$ values are saturated to a value of 0.9 or so, where no effect of grain size is observed. With increase in yield strength, $R s$ begins to decrease at a certain yield strength. Here, the yield strength where $R s$ corresponds to 0.85 is named as an SSC critical strength $\left(\sigma_{c}^{85}\right) ; R s$ is lower than 0.85 at yield strengths exceeding the yield strength equal to $\sigma_{c}^{85} \cdot \sigma_{c}^{85}$ is influenced by the grain size and becomes large with grain refinement. $R s$, however, is not influenced by the grain size at yield strengths below $\sigma_{c}^{85}$. Namely,

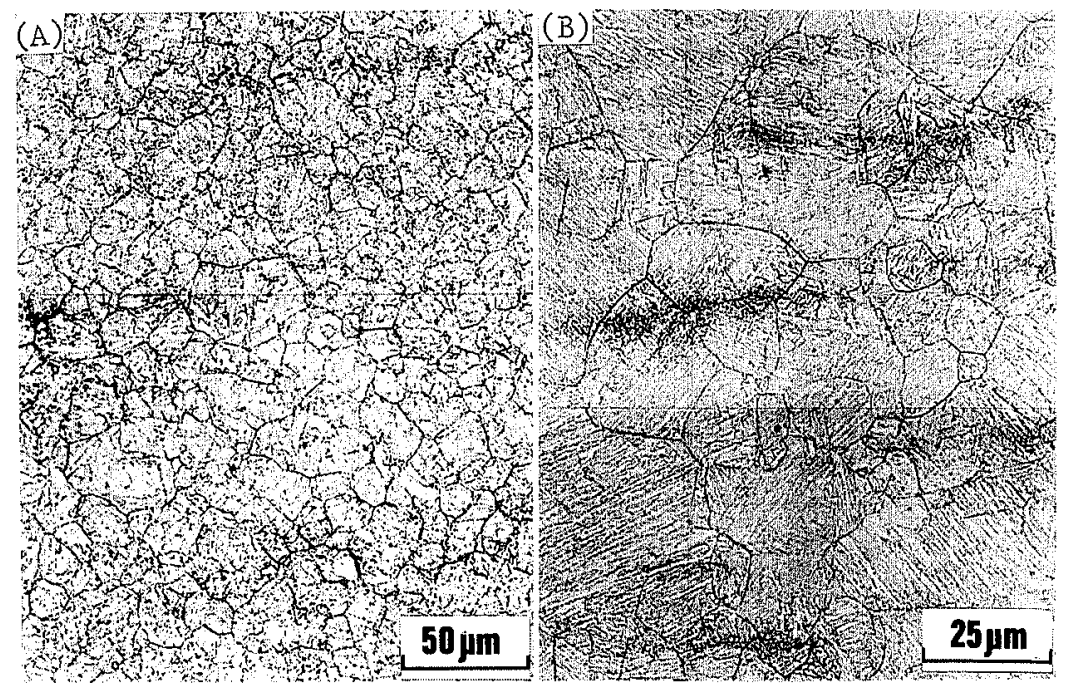

Fig. 2.

Examples of prior austenite grains. (steel LM) (A) $930^{\circ} \mathrm{C} \times 15 \mathrm{~min},(\mathrm{~B}) 1050^{\circ} \mathrm{C} \times 15 \mathrm{~min}$. 
the $\sigma_{c}^{85}$ represents $\mathrm{SSC}$ resistance for each quenched steel.

The experimental data for the steel HM and LM obtained in the same procedure above mentioned are presented in Fig. 7 and Fig. 8, respectively. The relations between yield strength and $R s$ are similar to that of Fig. 6 .

The results presented in Figs. 6, 7 and 8 are arranged in Fig. 9. It shows the change of $\sigma_{c}^{85}$ as the function of austenite grain size. $\sigma_{c}^{85}$ rises as austenite grain becomes small for steel with a given chemical composition. At a constant grain size, $\sigma_{c}^{85}$ is also affected by chemical compositions; an addition of Mo raises $\sigma_{c}^{85}$ by around $20 \mathrm{MPa}$ and a reduction of $1 \%$ of $\mathrm{Mn}$ raises $\sigma_{c}^{85}$ by around $70 \mathrm{MPa}$. It should be noted that the microstructures of steels in this study are tempered martensite and substantially the same, irrespective of chemical composition and grain size.

\subsection{Fractographic Observation of SSC Surface}

A fracture surface macroscopically consists of SSC surface and ductile fracture surface. The former is flat and perpendicular to the stress direction and the latter is the final portion of failure. Microscopic features of fracture surface of a specimen is the same in all of SSC surface. Scanning electron micrographs of typical SSC

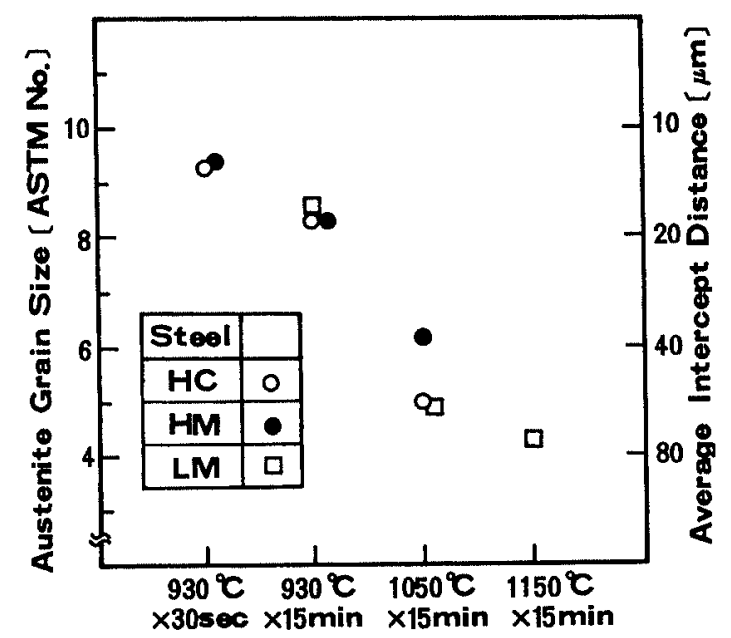

Fig. 3. Change of austenite grain size by austenitizing conditions. surfaces are shown in Fig. 10. Figures 10A, 10D, 10E are examples of transgranular fracture surfaces. Figures $10 \mathrm{~B}$, $10 \mathrm{C}, 10 \mathrm{~F}$ are examples of mixture of intergranular and transgranular cracks. Steels with high $R s$ of 0.9 level shows transgranular fractures, while intergranular cracks appear in steels with lower $R s$, irrespective of chemical composition, grain size and yield strength. For example, Figs. 10B and 10D are fracture surfaces of steels which are different only in grain size. Fine grained steel (Fig. 10D) with $R s$ of 0.95 shows fully transgranular fracture, while coarse grained steel (Fig. 10B) with $R s$ of 0.77 shows fracture containing intergranular cracks. Thus, intergranular cracks appear when $R_{s}$ is below 0.9 level. These observations show that intergranular cracks oc-
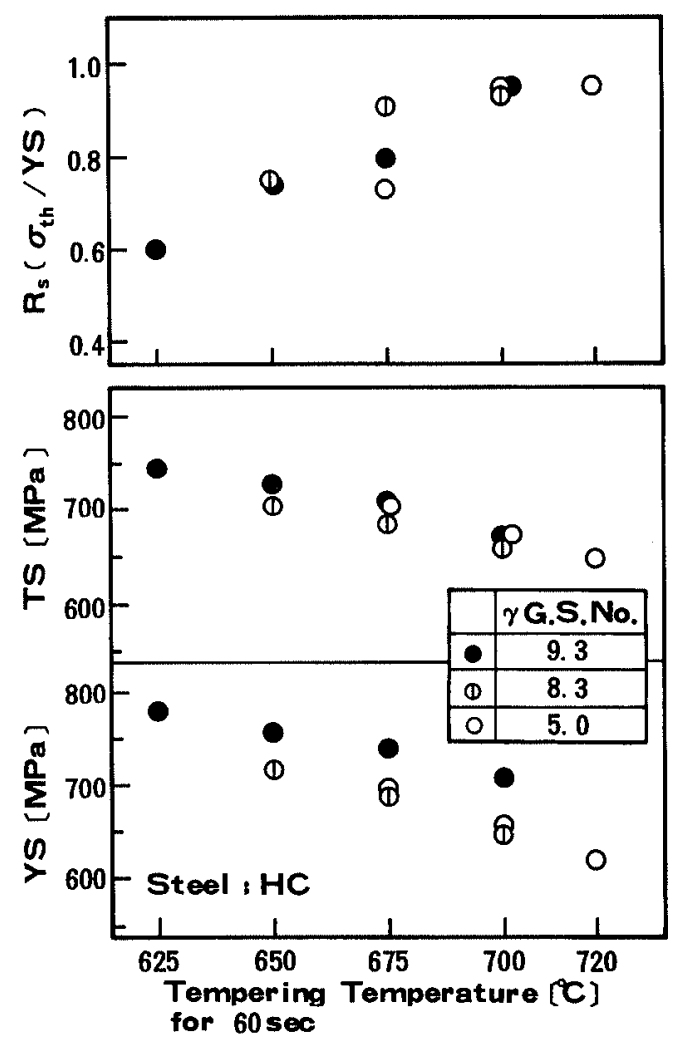

Fig. 4. Dependence of YS, TS and $R s$ on tempering temperature.

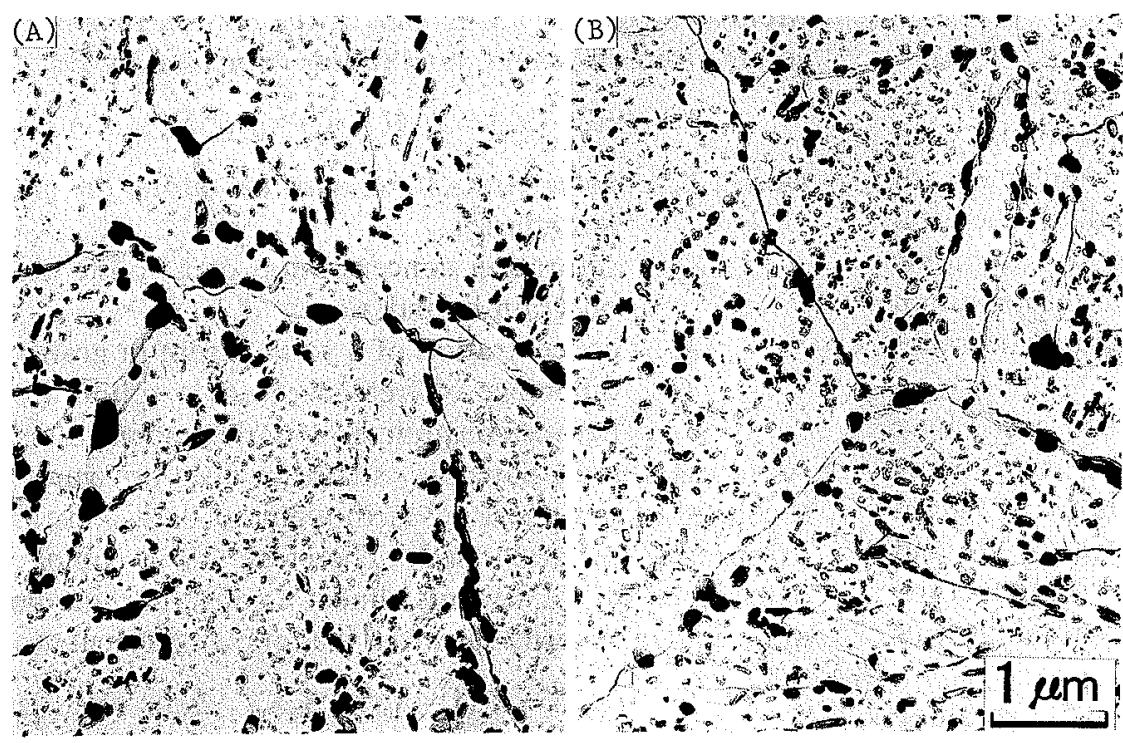

Fig. 5.

Extraction replica micrographs of steel $\mathrm{HC}$ with the same strength level and different grain size.

(A) G.S. No.: 8.3 , YS: $716 \mathrm{MPa}$, (B) G.S. No. 5.0, YS: $697 \mathrm{MPa}$. 


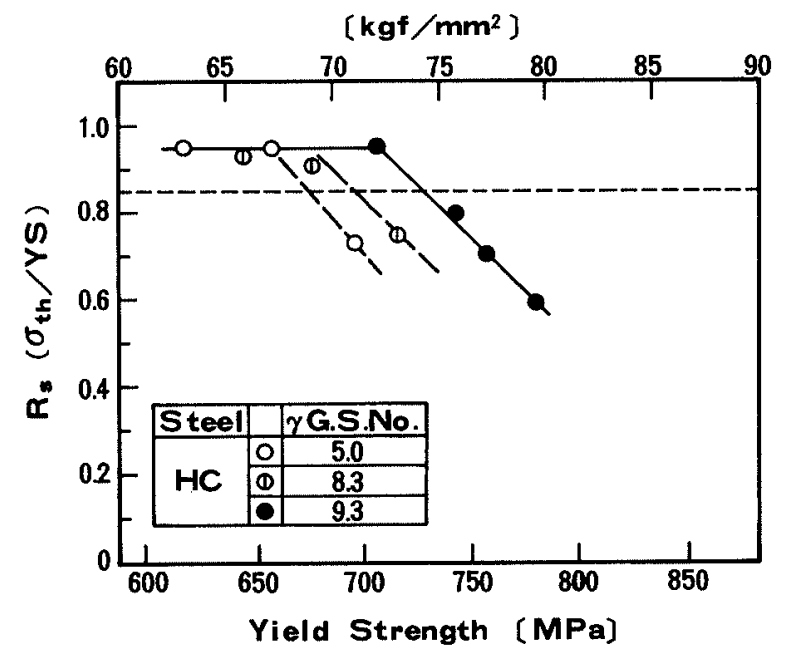

Fig. 6. Relation between yield strength and $R S$ value. $(1.5 \% \mathrm{Mn}-0 \% \mathrm{Mo})$

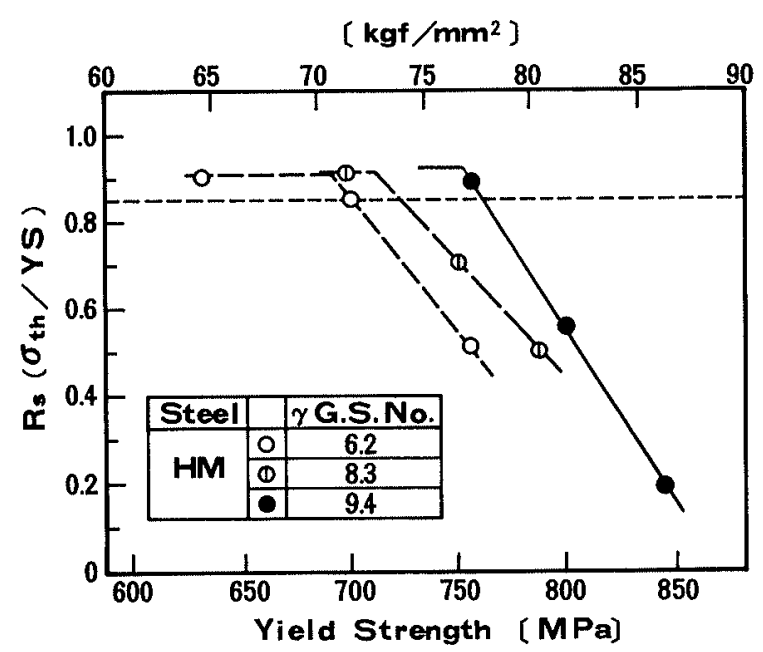

Fig. 7. Relation between yield strength and $R s$ value. $(1.5 \% \mathrm{Mn}-0.2 \% \mathrm{Mo})$

cur at yield strengths exceeding $\sigma_{c}^{85}$. It is clear that the $R s$ value decreases due to an occurrence of intergranular cracks, irrespective of chemical composition and grain size.

\section{Discussion}

$R s$ value, a normalized $\sigma_{t h}$ by the yield strength begins to decrease with increase in yield strength at the yield strength equal to $\sigma_{c}^{85} . \sigma_{c}^{85}$ rises with refinement of austenite grain size, also being influenced by chemical compositions as shown in Fig. 9. The fractographic observation reveals that $\sigma_{c}^{85}$ corresponds to the minimum yield strength for the occurrence of intergranular cracks as mentioned previously by the authors. ${ }^{11)}$

A change of $\sigma_{c}^{85}$ is easily supposed to be caused by a change in grain boundary strength, which is probably influenced by grain boundary segregation or grain boundary precipitation or the both. Changes of $\mathrm{Mn}$ and Mo in content presumably change the both factors, leading to the change in $\sigma_{c}^{85}$. Then, the mechanism of grain size on $\sigma_{c}^{85}$ will be discussed below.

First, the size and distribution of precipitates along

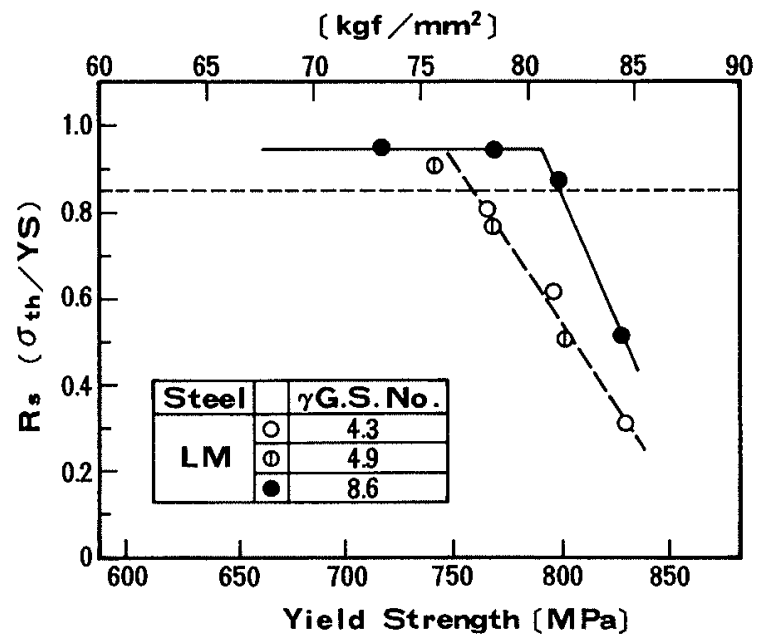

Fig. 8. Relation between yield strength and $R s$ value. $(0.5 \% \mathrm{Mn}-0.2 \% \mathrm{Mo})$

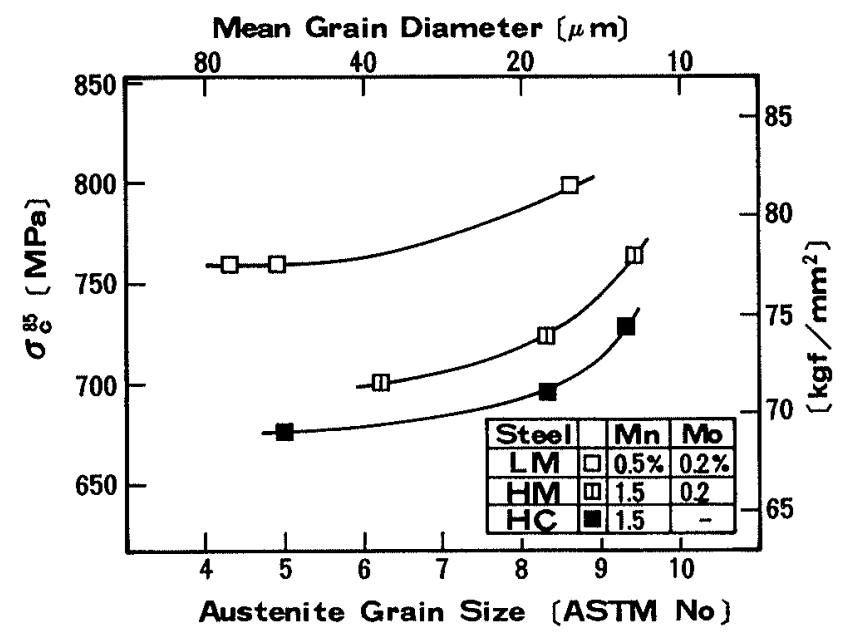

Fig. 9. Effects of austenite grain size and chemical compositions on $\sigma_{c}^{85}$.

grain boundaries are substantially the same for fine and coarse grains as shown in Fig. 5. Second, the amount of segregation on grain boundaries is supposed to be not affected by grain size. The reason is shown as follows. Assuming that grain boundary segregation follows the McLean's equilibrium model, ${ }^{12)}$ the concentration of a solute atom on grain boundaries is expressed by Eq. (1).

$$
X_{b} /\left(X_{b}^{0}-X_{b}\right)=X_{c} /\left(1-X_{c}\right) \exp (Q / k T)
$$

where, $X_{b}$ : concentration of a solute atom on grain boundaries,

$X_{b}^{0}$ : saturation concentration of a solute atom on grain boundaries,

$X_{c}$ : concentration of a solute atom in grains,

$Q:$ difference of free energy of a solute atom between on grain boundaries and in grains.

As far as a grain boundary structure does not vary by a change of grain size, $Q$ is thought to be a constant, irrespective of grain size. Therefore $X_{b}$ is uniquely determined by $X_{c}$, which is almost a constant regardless of grain size as easily shown in the following calculation.

$$
X=X_{c}\left(1-S_{v} t\right)+X_{b} S_{v} t
$$



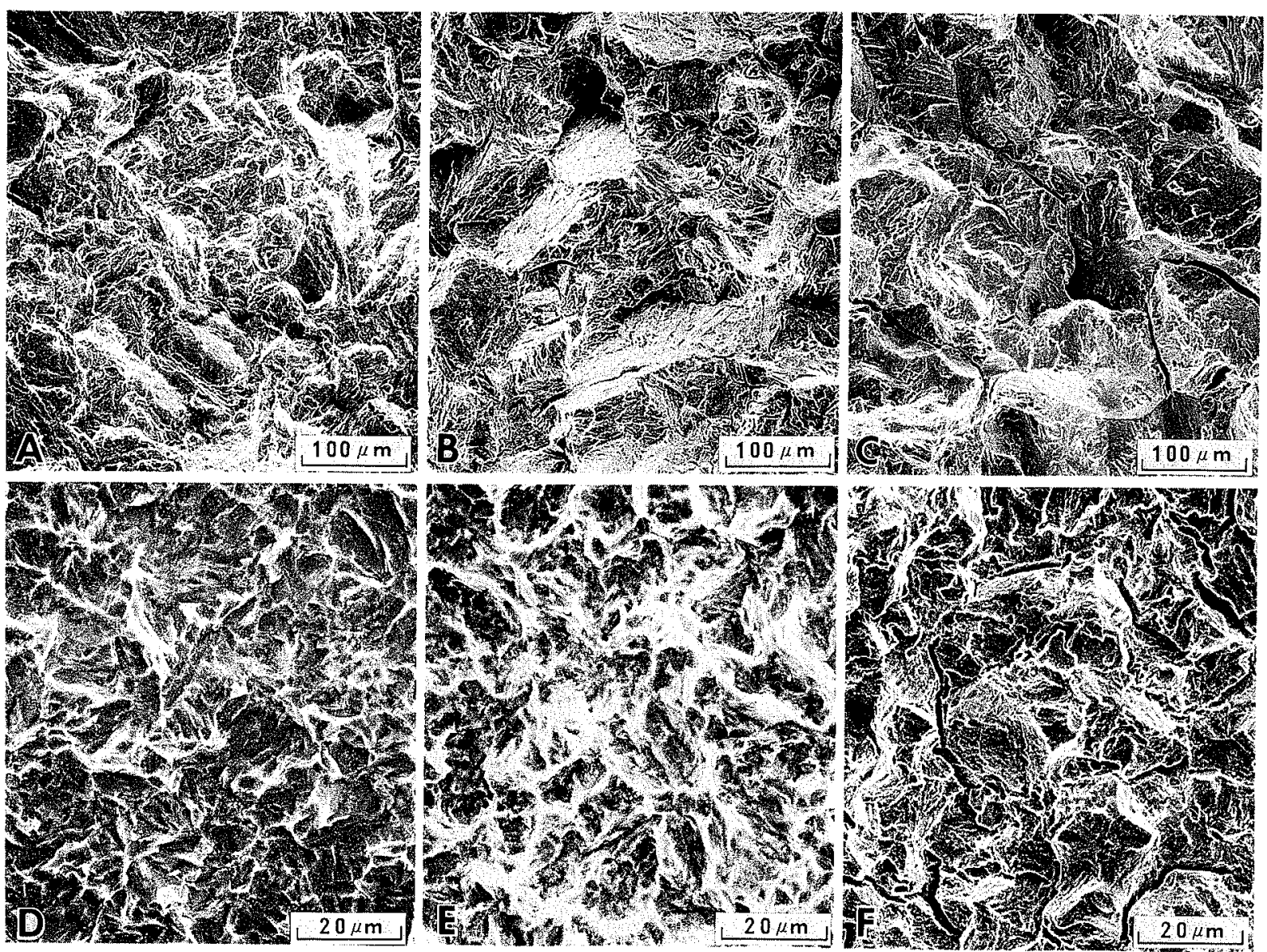

Fig. 10. Scanning electron micrographs of typical SSC surfaces.

(Steel, Grain size No., YS, Rs)
(A) LM, \#4.9,742 MPa, 0.91
(B) LM, \#4.9, 767 MPa, 0.77
(C) LM, \#4.3, $829 \mathrm{MPa}, 0.35$

(D) $\mathrm{LM}, \# 8.5,769 \mathrm{MPa}, 0.95$

(E) $\mathrm{HC}, \# 9.3,707 \mathrm{MPa}, 0.95$

(F) $\mathrm{HC}, \# 9.3,780 \mathrm{MPa}, 060$

where, $X:$ average concentration of a solute atom of a material,

$S_{v}$ : grain boundary surface area under the normalizing condition that the average grain volume is a unit volume,

$t$ : grain boundary thickness.

Considering $S_{v} t$ is small, the equation can be rewritten as follows:

$$
X_{c}=X /\left(1+\left(X_{b} / X_{c}\right) S_{v} t\right)
$$

Now it can be reasonably estimated that $S_{v}$ is about $3 / r$ where $r$ is a grain radius, $t$ is $1 \mathrm{~nm}$ and $\left(X_{b} / X_{c}\right)$ is at most $100,{ }^{13)}$ and that the difference of $X_{c}$ between for $r$ of $10 \mu \mathrm{m}$ and for $r$ of $100 \mu \mathrm{m}$ is $3 \%$ or so. Therefore, the change of a concentration of grain boundary segregation due to grain size change is regarded to be negligible small.

As shown in Fig. 4, a tempering temperature where $R s$ starts to decline is equal for any grain sizes. This suggests that intergranular fracture occurs at a constant tempering temperature, that is, at a constant segregation concentration regardless of grain size. However, yield strength at a constant tempering temperature rises with a reduction in grain size due to grain refinement strengthening. Thus, $\sigma_{c}^{85}$ of fine grain steel increases. When $R s$ is plotted as a function of tensile strength which little depends on grain size, all data are actually on a simple relationship (Fig. 11). In conclusion, the following

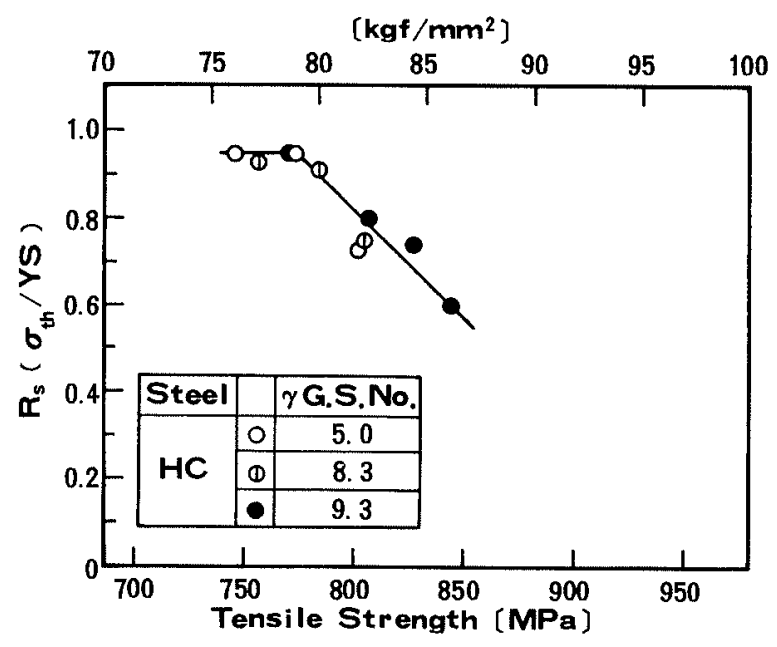

Fig. 11. Relation between tensile strength and $R s$.

model is presented: A change in $\sigma_{c}^{85}$ is primarily caused by a rise in yield strength due to grain refining strengthening under a constant grain boundary strength condition.

\section{Conclusions}

Effects of austenite grain size on SSC resistance were investigated using the constant load SSC test and the 
fractographic observation technique on SSC surface for low alloy tempered martensite steels with the variation in $\mathrm{Mn}$ and Mo contents. The important conclusions drawn from the present work are as follows:

(1) $R s$ value ( $\sigma_{t h} /$ yield strength) begins to decrease with increase in yield strength at the yield strength equal to $\sigma_{c}^{85} \cdot \sigma_{c}^{85}$ corresponds to the minimum yield strength for the occurrence of intergranular fracture.

(2) $\sigma_{c}^{85}$ rises with refinement in austenite grains, while $R s$ is not affected by austenite grain size at yield strengths below $\sigma_{c}^{85} \cdot \sigma_{c}^{85}$ at a constant grain size is influenced by chemical compositions; $\sigma_{c}^{85}$ is lowered by an increase in $\mathrm{Mn}$ and is raised by an addition of Mo.

(3) The model which can explain the present experimental relations for the effect of austenite grain size on $\sigma_{c}^{85}$ is as follows: An increase in $\sigma_{c}^{85}$ with grain refinement is primarily caused by a rise in yield strength due to grain refinement strengthening under a constant grain boundary strength condition.

\section{REFERENCES}

1) R. S. Treseder: Stress Corrosion Cracking and Hydrogen Embrittlement of Iron Base Alloys, ed. by R. W. Staehle, J.
Hockmann, R. D. McCright and J. E. Slater, NACE, Houston, (1977), 147

2) T. Sato, H. Higashiyama, $K$. Yamamoto, $T$. Inoue and $M$. Ueno: Proc. of Offshore Technology Conf., (1989), Paper No. 4331.

3) A. Ikeda, S. Nagata, T. Tsumura, Y. Nara and M. Kowaka: Symposium on Line Pipe and Tubular Goods at the API Production Dept., 1977 Standardization Conference, Florida, (1977), No. SS-5: 1.

4) M. Tanimura, Y. Ishizawa and T. Simada: Corros. Prev. Control, Feb. (1984), 5.

5) C. D. Kim and F. Baldy: Proc. of 8th ETCE, ASTM, (1985), 83.

6) F. R. David, G. C. Guntz and MF. J. Galis: Corrosion/89, NACE, (1989), Paper No. 474.

7) H. Asahi, Y. Sogo, M. Ueno and H. Higashiyama: Corrosion, 45 (1989), 519.

8) R. P. M. Proctor and H. W. Paxton: Trans. Am. Soc. Met., 62 (1969), 989.

9) J. F. Lessar and W. W. Gerberich: Metall. Trans. A, 7A (1976), 953.

10) NACE Standard TM0177-90, NACE, Houston, (1990).

11) H. Asahi, Y. Sogo, M. Ueno and H. Higashiyama: Metall. Trans. A, 19A (1988), 2171.

12) D. Mclean: Grain Boundaries in Metals, Oxford Univ. Press, (1957), 116

13) K. Tatsumi, N. Okumura and M. Yamamoto: J. Phys., Colloque, Interface Sci. Eng. '87, (1988), C5-699. 